\title{
Hue naming: A test of the validity of Werner and Wooten's average observer
}

\author{
KENNETH FULD and ANNE MARIE ALIE \\ University of New Hampshire, Durham, New Hampshire
}

\begin{abstract}
Fifteen subjects scaled monochromatic lights ranging from 460 to $640 \mathrm{~nm}$ by assigning percentages to the names blue, green, yellow, and red, representing the proportion of these hues perceived in the lights. The resulting hue-naming functions were compared to those predicted from the opponent-chromatic response functions of Werner and Wooten's $(1979 \mathrm{~b})$ proposed average observer. The agreement between the two sets of functions was reasonably good, which strengthens the validity of their average observer.
\end{abstract}

Jameson and Hurvich (1955) were the first to measure quantitatively the spectral responsivity of the opponentchromatic channels, which were initially proposed by Hering (1920/1964) in his opponent-colors theory. These quantitative measurements have since been replicated by others (Romeskie, 1978; Werner \& Wooten, 1979a), using the same hue-cancellation technique as that used by Jameson and Hurvich.

Werner and Wooten (1979b) have presented opponentchromatic response functions for the average observer. The functions are based on the data of seven subjects from three studies (Jameson \& Hurvich, 1955; Romeskie, 1978; Werner \& Wooten, 1979a). The importance of these functions, as Werner and Wooten (1979b) point out, is that they are useful for quantitative modeling when assumptions must be made about a standard or average psychophysical observer. Before such functions can be used with confidence, however, their validity must be tested. One way to do this is to examine the extent to which the opponent-chromatic response functions for the average observer predict hue naming for a large group of subjects. Werner and Wooten (1979a) have shown individual opponent-chromatic response functions to be good predictors of the same individuals' hue-naming data. These same subjects' hue-naming functions have, in fact, been compared by Werner and Wooten (1979b) to the predicted functions of their average observer. But the average observer is based partly on these same subjects, so it is not surprising that the comparison was favorable. What is needed is a comparison of the predicted hue-naming functions from Werner and Wooten's average observer with those functions empirically obtained from a completely different population of subjects. That was the main purpose of the present study. Also, the subjects upon whom the average observer is based were not all experimentally naive and were all reasonably well practiced. Do their data generalize to naive and virtually unpracticed subjects? In the present study, this question was addressed as well.

The authors' mailing address is: Department of Psychology, University of New Hampshire, Durham, NH 03824.

\section{METHOD}

\section{Subjects}

Fifteen male, undergraduate students, enrolled in an introductory psychology course at the University of New Hampshire, served as subjects. Their color vision was assessed as normal on the basis of results from the administration of the Ishihara Pseudoisochromatic Test Plates and the Farnsworth Dichotomous Panel D-15 Test. The subjects ranged in age from 18 to 26 years.

\section{Apparatus}

A one-channel projection optical system was used. Light was provided by a $108-W$, tungsten ribbon filament, microscope lamp and was rendered monochromatic by a J-Y Optical Systems $\mathrm{H}-10$ monochromator (nominal half-band width of $8 \mathrm{~nm}$ ). Control of luminance was achieved by the use of a neutral density wedge. A mechanical shutter allowed for control of the stimulus duration. A field stop, placed in a collimated portion of the optical system, provided a $1.0^{\circ}$ circular test field, which transilluminated a diffuse, white, paper screen $\left(3.2^{\circ}\right.$ in diameter), which the subject viewed from a distance of $70 \mathrm{~cm}$. The subject's head position was maintained by a chin- and foreheadrest. Light baffling was used in order to reduce stray light.

\section{Calibration}

The relative spectral energy of each test field was measured by placing a calibrated detector head of a United Detector Technologies radiometer (Model 61) on the subject's side of the viewing screen. The neutral density wedge was calibrated every $30 \mathrm{~nm}$ with the same radiometer. The photometric calibration was carried out with a Litemate/Spotmate System $\mathbf{5 0 0}$ photometer.

\section{Procedure}

Each subject was initially tested in order to establish the normalcy of color vision in his right eye. He was then read a set of instructions explaining his task in the experiment. The subject then viewed with his right eye a $1.0^{\circ}$ circular test field that varied randomly in wavelength from 460 to $640 \mathrm{~nm}$ in steps of $10 \mathrm{~nm}$. Each stimulus was presented foveally for $2 \mathrm{sec}$. No fixation was used. The subject was asked to assign percentages to the hue names red, green, yellow, and blue, representing the proportion of each of these hues perceived in a given test field. He was not told that the total percentage must equal 100, although in all cases the responses did in fact sum to 100 . The subject was permitted to see a light repeatedly, with 10 -sec dark intervals between presentations, until a final judgment could be made. Typically, a subject required only two presentations, and rarely did the number of presentations exceed four. Given this low rate of stimulus presentation in combination 
with 10-sec dark intervals, 2-sec test-field exposures, and a testfield luminance of $1.0 \mathrm{~mL}\left(3.2 \mathrm{~cd} / \mathrm{m}^{2}\right)$, the contribution of any effects of chromatic adaptation was almost certainly obviated (see Crawford, 1943; Johannsen, 1934). After the subject's response, an approximately 30-sec dark period followed, which was, in turn, followed by the presentation of a test field of a different wavelength. This pattern was repeated until all 19 wavelengths had been presented. Two additional sets of 19 trials followed this. The first of these three sets, which lasted approximately $20 \mathrm{~min}$, constituted practice and served to adapt the subject to the experimental light level.

Test fields were equated for brightness on the basis of Wagner and Boynton's (1972) relative spectral efficiency function determined by the step-by-step method. The lights were equal to the brightness of a $580-\mathrm{nm}$ light of $1.0 \mathrm{~mL}\left(3.2 \mathrm{~cd} / \mathrm{m}^{2}\right)$. This was the maximum luminance that could be achieved for equal brightness across the chosen range of wavelengths.

\section{RESULTS AND DISCUSSION}

The thick lines in Figure 1 show the average huenaming responses for the 15 subjects in the present study. Each point represents the mean of 30 responses. Plus and minus 1 standard error of the mean are indicated by the vertical lines through each of the data points. Where percent hue was less than five, we considered this to be noise, and no point was plotted. In such cases, the residual amount was divided equally among the remaining hue categories that were used to describe the light and added to them. This was done so that the total response summed to 100 . The figure shows the spectral loci for unique blue, green, and yellow to be at $460-470,510$, and $582 \mathrm{~nm}$, respectively. The wavelength for unique yellow was determined by the point where the green and red response functions cross each other. Our values are in agreement with those found by others (Dimmick \& Hubbard, 1939) and particularly with those determined by color-naming

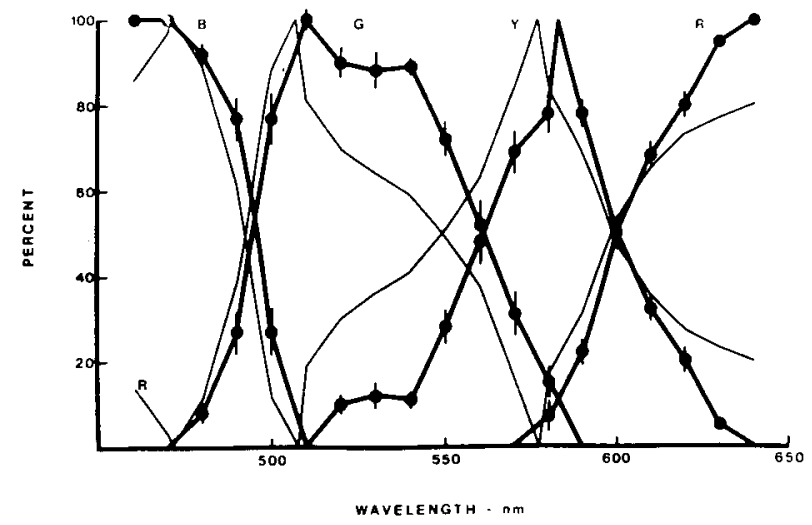

Figure 1. Hue-naming functions for the 15 subjects in the present experiment (thick lines) and functions predicted by Werner and Wooten's average observer (thin lines). On the axis of ordinates is the percent blue, green, yellow, or red (denoted by the letters B, $\mathbf{G}, \mathbf{Y}$, and $\mathbf{R}$, respectively) reported as perceived in test fields of various wavelengths, which are shown on the axis of abscissas. Each point (thick lines) represents the mean of 30 responses ( 2 per subject). Vertical lines through the data points show \pm 1 standard error of the mean. techniques (Beare, 1963; Boynton, Schafer, \& Neun, 1964; Thomson, 1954).

The thin lines in Figure 1 are the predicted hue-naming functions for the average observer, derived from Table 1 of Werner and Wooten (1979b), which gives the average opponent-chromatic valences, and from the following equations from Hurvich and Jameson's (1955) model:

$$
\begin{aligned}
& \mathrm{h}_{(\mathrm{r}, \mathrm{g}) \lambda}=\frac{(|\mathrm{r}-\mathrm{g}|)_{\lambda}}{(|\mathrm{r}-\mathrm{g}|+|\mathrm{y}-\mathrm{b}|)_{\lambda}} \\
& \mathrm{h}_{(\mathrm{y}, \mathrm{b}) \lambda}=\frac{(|\mathrm{y}-\mathrm{b}|)_{\lambda}}{(|\mathrm{r}-\mathrm{g}|+|\mathrm{y}-\mathrm{b}|)_{\lambda}}
\end{aligned}
$$

where $h_{(\mathrm{r}, \mathrm{g})}$ is the hue coefficient for the red-green channel and should predict perceived redness or greenness; $\mathrm{h}_{(\mathrm{y}, \mathrm{b})}$ is the hue coefficient for the yellow-blue channel and should predict yellowness or blueness; $r-g$ and $y-b$ are the red-green and yellow-blue chromatic valences, respectively; $\lambda$ is wavelength.

Although the agreement between the two sets of functions is reasonably good, there are notable differences. The red and green functions from the present experiment are broader than those predicted by the average observer, and the yellow function is narrower. Unique green and unique yellow occur at slightly longer wavelengths than those predicted by the average observer. Finally, no red is reported at $460 \mathrm{~nm}$, while the average observer theoretically reports a significant amount $(14 \%)$. The mean absolute difference between the points of the two sets of hue-naming functions is $13.7 \%$. That the agreement is not better could be due to at least three things.

First, the predicted functions are based on studies in which the luminance ranged from approximately 2.3 to $10 \mathrm{~mL}\left(7.3\right.$ to $\left.31.8 \mathrm{~cd} / \mathrm{m}^{2}\right)$. In the present study, the test fields were equated in brightness to a $580-\mathrm{nm}$ light of $1.0 \mathrm{~mL}\left(3.2 \mathrm{~cd} / \mathrm{m}^{2}\right)$. Thus, a Bezold-Brücke hue shift could account for part of the difference. We adjusted the predicted functions to compensate for this in the following manner. We first fit a smooth function (by eye) through the data of Purdy (1937) and Akita and Graham (1966), where $\Delta \lambda$ was plotted as a function of $\lambda$. $\Delta \lambda$ was the difference in wavelength between a field of approximately $10 \mathrm{~mL}\left(31.8 \mathrm{~cd} / \mathrm{m}^{2}\right)$ and one of approximately $1 \mathrm{~mL}\left(3.2 \mathrm{~cd} / \mathrm{m}^{2}\right)$, when both fields were perceived to be equal in hue. We then plotted the predicted percent hue from the thin-lined functions in Figure 1 for the wavelength to which the standard in these studies was matched, but at the wavelength of the standard. After this adjustment, the mean absolute difference between the two sets of points was reduced to $13.1 \%$. The slightly lower luminance level used in the present study thus appears to account for little of the difference between the predicted and obtained results.

Another factor that may have contributed to the differ- 
ence between the two sets of data was the relatively unpracticed condition of our subjects. The subjects upon whose data Werner and Wooten's average observer is based, although in many cases experimentally naive, were all well practiced. Our subjects received very little practice, by design. We felt that the validity of the average observer could be strengthened if it could be shown that such an observer could predict the behavior of naive and unpracticed subjects. That practice may be a relevant factor in hue naming was pointed out by Werner and Wooten (1979a). They noted that the amount of yellowness reported by their subjects for long-wave lights progressively increased over the course of their practice sessions. Depending on the specific condition of an experiment (e.g., luminance level), such practice effects may extend to other parts of the spectrum.

A third factor that may account for some of the difference between the predicted and obtained functions is the ability of the opponent-chromatic response functions to predict hue naming. Werner and Wooten (1979a) have shown that such predictions can be made only to a first approximation. In their study, they compared hue-naming functions, predicted from the opponent-chromatic response functions of an individual, with those same individual's actual hue-naming data. For three subjects, the mean absolute difference between the two sets of functions was $11.2 \%$. Most of the difference was attributed to the variance in the opponent mechanisms. Our difference of $13.7 \%$ thus compares favorably.

In conclusion, given the substantially different conditions of our experiment compared with those from which Werner and Wooten's average observer was derived, and considering the reasonably close agreement between the average observer's predicted hue-naming functions and those obtained in the present study, we feel that we have strengthened the validity of Werner and Wooten's average observer.

\section{REFERENCES}

Akita, M., \& Graham, C. H. (1966). Maintaining an absolute test hue in the presence of different background colors and luminance ratios. Vision Research, 6, 315-323.

Beare, A. C. (1963). Color-name as a function of wavelength. American Journal of Psychology, 76, 248-256.

Boynton, R. M., Schafer, W., \& Neun, M. E. (1964). Huewavelength relation measured by color-naming method for three retinal locations. Science, 146, 666-668.

CRAwFORD, B. H. (1943). Photochemical laws and visual phenomena. Proceedings of the Royal Society (London), B, 133, 63-75.

Dimmick, F. L., \& HubBaRd, M. R. (1939). The spectral location of psychologically unique yellow, green, and blue. American Journal of Psychology, 52, 242-254.

HERING, E. (1964). Outlines of a theory of the light sense (L. M. Hurvich \& D. Jameson, Trans.). Cambridge, MA: Harvard University Press. (Original work published 1920)

HURVICH, L. M., JAMESON, D. (1955). Some quantitative aspects of an opponent-colors theory. II. Brightness, saturation, and hue in normal and dichromatic vision. Joumal of the Optical Society of America, 45, 602-616.

JAMESON, D., HURVICH, L. M. (1955). Some quantitative aspects of an opponent-colors theory. I. Chromatic responses and spectral saturation. Journal of the Optical Society of America, 45, 546-552.

JoHANNSEN, D. E. (1934). The duration and intensity of the exposure light as factors in determining the course of the subsequent darkadaptation: II. Threshold method. Journal of General Psychology, 10, 20-41.

PuRDY, D. M. (1937). The Bezold-Brücke phenomenon and contours for constant hue. American Journal of Psychology, 49, 313-315.

Romeskie, M. (1978). Chromatic opponent-response functions of anomalous trichromats. Vision Research, 18, 1521-1532.

Thomson, L. C. (1954). Sensations aroused by monochromatic stimuli and their prediction. Optica Acta, 1, 93-102.

WAGNer, G., \& Boynton, R. M. (1972). Comparison of four methods of heterochromatic photometry. Journal of the Optical Society of America, 62, 1505-1515.

Werner, J. S., \& WoOten, B. R. (1979a). Opponent chromatic mechanisms: Relation to photopigments and hue naming. Journal of the Optical Society of America, 69, 422-434.

WERner, J. S., \& WOOTEN, B. R. (1979b). Opponent chromatic response functions for an average observer. Perception \& Psychophysics, 25, 371-374. 